\title{
REPRESENTAÇÕES DO CORPO EM UMA REVISTA DE NEGÓCIOS
} BODY REPRESENTATIONS IN A POPULAR BUSINESS MAGAZINE

\author{
Cláudia Sirangelo Eccel, Carmem Lígia Iochins Grisci e Leonardo Tonon \\ Universidade Federal do Rio Grande do Sul, Porto Alegre, Brasil
}

\section{RESUMO}

O presente artigo resulta de uma pesquisa exploratória que procurou analisar como uma revista de negócios representa o corpo através do que veicula em suas reportagens. As representações encontradas foram categorizadas em dois grupos - gênero e estilo - analisados de acordo com referenciais teóricos sobre o trabalho e o corpo na contemporaneidade. Foi possível identificar que a representação dos corpos na revista passa por uma homogeneização dos estilos de vida no meio executivo. Verificaram-se ainda elementos relativos às prescrições quanto à normalização e adaptação dos corpos a um dado modelo de sucesso profissional que ultrapassa as maneiras de trabalhar e invade a subjetividade dos indivíduos. Além disso, a análise permitiu um olhar sobre o corpo construído e significado de acordo com as exigências da atual sociedade de consumo.

Palavras-chave: corpo; subjetividade; gênero.

\begin{abstract}
This article results from an exploratory study that aimed to analyze how a business magazine represents the body in its reporting. The body representations found were categorized into two groups - gender and style - analyzed in accordance with theoretical references about work and body in the contemporary. Considering the results, it was possible to identify that the body representations in the journal goes through a homogenization of executive's lifestyles. There was also information regarding requirements for standardization and adaptation of the bodies to a particular model of professional success that goes beyond the ways of working and invades the individual's subjectivity. Furthermore, the analysis allowed a glimpse into the body as being built and signified according to the demands of today's consumer society.
\end{abstract}

Keywords: body; subjectivity; gender.

\section{Introdução}

Pesquisas acadêmicas sobre assuntos relacionados à gestão em mídias populares de negócios, especificamente revistas, possibilitam uma visão acerca do discurso gerencial popularmente disseminado, como ilustram pesquisas de Wood Jr. e Paula (2002), Cappelle, Mageste, Mello e Brito (2003), Morin e Rodrigues (2004), e Mazza e Alvarez (2000). O presente artigo resulta de uma pesquisa que buscou compreender como se dão as representações dos corpos dos trabalhadores na revista Você $S / A$, publicada por uma grande editora, com distribuição nacional. A partir de uma análise de conteúdo (Bardin, 1979), tomaram-se duas categorias específicas: gênero e estilo - composto por estética e comportamento, englobando não só o corpo como um aparato físico, mas o corpo em ato.

Foi possível identificar que a apresentação dos corpos na revista Você $S / A$ promove uma homogeneização dos estilos de vida no meio executivo, seja em suas formas estéticas, seja nas condutas. Propõe-se, com isso, uma crítica à normalização e adaptação dos corpos a um dado modelo de sucesso profissional que ultrapassa as maneiras de trabalhar e invade a subjetividade, moldando maneiras de ser, de se comportar, alimentar, vestir, viver. Esse modelo não apenas limita os estilos de vida dos executivos, como tende fortemente a excluir aqueles que se distanciam, como desviantes. Além disso, pretendese olhar para os corpos como mais do que instrumentos para a produção, já que esses são construídos a partir do contexto e das significações que lhes são atribuídas.

Desse modo, este artigo remete, inicialmente, à realidade social atual, às mudanças no mundo do trabalho e suas consequências para os indivíduos. Na sequência, são abordados aspectos teóricos sobre o corpo no seu contexto sócio-histórico e nos estudos organizacionais. Posteriormente são esclarecidos os aspectos da realização da pesquisa no que se refere à escolha da mídia e aos procedimentos metodológicos. Em seguida, são apresentados os resultados encontrados na pesquisa, através de uma análise crítica, e as considerações finais. 


\section{O trabalho na contemporaneidade}

A centralidade que as organizações empresariais assumem no mundo contemporâneo tem sido constantemente afirmada. As empresas privadas, especialmente multinacionais, passaram a ocupar um espaço no imaginário social que ultrapassa aquele puramente profissional, atuando como propagadoras de padrões de comportamento e valores.

Dentre as diversas mudanças ocorridas na modernidade, no que se referem à produção, as novidades tecnológicas, a flexibilização da legislação trabalhista e a mobilidade do capital modificaram irremediavelmente o trabalho e as demais relações sociais, construindo uma nova realidade, denominada por Bauman (2001) de modernidade líquida. O trabalho, nesse entorno, passou a ser o trabalho líquido que, apoiado em tênues pilares, exige do trabalhador um exercício contínuo de qualificação frente a exigências crescentes e mutantes, que não se limita à força física dos corpos.

$\mathrm{Na}$ contemporaneidade, em especial a partir da década de 1980, um maior direcionamento para o consumo contribuiu para que o trabalho intensificasse suas características imateriais. $\mathrm{O}$ trabalho imaterial, que não se limita à produção de objetos, enaltece um saber fazer que, por sua vez, é capaz de redefinir o próprio trabalhador (Lazzarato \& Negri, 2001), fazendo com que cada indivíduo passe a ser, concomitantemente, produto e produtor do sistema (Gaulejac, 2007). Dessa forma, numa sociedade que prima pelo consumo, vendem-se mais do que produtos, vendem-se formas de vida (Pelbart, 2003).

As mudanças ocorridas implicaram igualmente fatores relativos ao controle, cabendo destacar que as formas de controle da sociedade atual em muito diferem daquelas vivenciadas em tempos passados. O panóptico cede lugar ao sinóptico numa experiência de controle em que todos observam a todos: o controle é social (Bauman, 1999). Nesse sentido, Foucault (1977/1996) diferencia a sociedade disciplinar - organizada a partir de instituições de confinamento e rigidez de regras - da sociedade de controle - caracterizada pela internalização das regras, que resulta a incumbência da fiscalização ao próprio indivíduo. Na forma de autocontrole, o controle encontra menos chances de resistência (Foucault, 1977/1996).

Foucault (2008) reflete ainda acerca do fato de que a "governamentabilidade", antes exercida pelo Estado, passa a ser estabelecida segundo os interesses e as exigências do mercado, denominando tal fenômeno como biopolítca neoliberal. Nesse sentido, Pelbart (2003) considera que a biopolítica se dirige aos homens como espécie, com o poder de atingir a vida de ponta a ponta. Trata-se, portanto, de um controle sobre os aparelhos de produção, de uma abordagem da vida como objeto político, tomada pelo poder. Em suma, as novas formas de governo dos corpos e das almas consistem na aquisição de competências que sejam adequadas ao mercado neoliberal, as quais estão diretamente ligadas a fatores como a saúde e a beleza dos corpos produtivos (César \& Duarte, 2009).

Por fim, é possível salientar que, devido às transformações do trabalho, também as formas de dominação do capital sobre os trabalhadores se modificaram, tornando-se progressivamente mais sutis, internalizadas e, ao mesmo tempo, mais generalizadas, demonstrando maior potência na produção de subjetividade. Nesse sentido, as forças biopolíticas agem moldando subjetividades, considerando a totalidade do corpo e da alma.

\section{Aspectos teóricos sobre corpo e gênero}

\section{Corpo e gênero no contexto histórico-social}

Há tempos o corpo vem sendo objeto constante de estudo das ciências biológicas, humanas e sociais. Nesse sentido, Tucherman (2004) afirma que esse se enquadra em uma das categorias mais persistentes de nossa cultura, na medida em que pôde suportar diversas transformações.

Do culto físico dos gregos aos flagelos corporais cristãos, o corpo foi submetido às mais distintas mudanças sociais e psíquicas. Entretanto, foi com a ascensão do capitalismo, e consequente valorização do individualismo, que se viu emergir um novo padrão corporal. Novas técnicas científicas inauguraram outras formas de lidar com o corpo, como no caso das cirurgias plásticas ou mesmo da tecnologia genética, ao possibilitarem mudanças em relação aos elementos antes ligados diretamente à natureza. Essas novas tecnologias possibilitam refletir sobre o corpo "próprio mas não tropo" (Tucherman, 2004, p. 47), uma vez que esse é unido a um entorno, que fornece padrões e saberes sobre seu funcionamento.

Pensando o corpo na contemporaneidade, Sant'Anna (2001) aponta para as mudanças impostas pelas novas tecnologias e pela relação com o tempo e o espaço. Para a autora, a partir da modernidade o corpo começou a ser visto como algo que se tem, e não aquilo que se é, sendo que da máquina a vapor à Internet, os corpos foram se submetendo e moldando às novas exigências.

Por vezes, essa adaptação se estabeleceu historicamente por meio da docilização do corpo físico, como aponta Foucault (1977/1996). Um corpo que pode ser submetido, utilizado, transformado ou mesmo aperfeiçoado. Nesse processo, a disciplina passa a ser uma das responsáveis pela concretização das novas formas de poder que envolvem o corpo (Foucault, 1977/1996).

Louro (2000) afirma que os corpos são constantemente avaliados, classificados e moldados às convenções sociais. As marcas impressas nos corpos, como gênero e etnia, por exemplo, servem de identificadores sociais facilmente "observáveis" a partir do olhar. Nessa imputação de 
identidades operam os jogos de poder nos quais os homens brancos são sempre mais valorizados do que mulheres e não brancos. Dentre todas as classificações, no entanto, Louro (2000) aponta a sexualidade como a categoria primordial de diferenciação e definição dos indivíduos.

A esse aspecto, é necessário ainda acrescentar-se as ideias desenvolvidas por Butler (2003), a partir das quais vê-se que o gênero, como categoria de diferenciação social, também abrange a esfera política que organiza a sociedade. A autora propõe que a naturalização do sexo, como pré-discursivo - ou natural -, deve ser entendida como uma consequência do próprio regime de gênero, a fim de manter a dicotomia masculino/feminino. Nesse sentido, Butler (2003) critica a limitação em apenas dois gêneros possíveis, além da vinculação compulsória do gênero com o sexo, visto que, nesse caso, a distinção entre os constructos se torna inócua.

Além disso, gênero torna-se uma dimensão visível apenas para os corpos marcados pela diferença sexual, ou seja, não aparece como uma categoria de diferenciação para os homens, já as mulheres são distinguidas pela condição feminina. Os homens são, como descreve Butler (2003), "portadores de uma pessoalidade universal que transcende o corpo" (p. 28).

De modo geral, as exposições até aqui mencionadas permitem refletir acerca da visão do corpo enquanto ato, sendo que esse, por sua vez, vem sendo apropriado pelas mais diferentes esferas sociais. O meio organizacional corresponde a uma dessas esferas na medida em que se apropria de elementos relacionados ao corpo, conforme poderão ser apreciadas as considerações na sequência.

\section{Corpo e gênero nos estudos organizacionais}

Nos estudos organizacionais, tradicionalmente o corpo tem sido compreendido como instância física separada da mente e estudado apenas como um meio para a produção. Recentemente é que outras concepções sobre o corpo passaram a ser contempladas também nessa área, e autores apontaram para a não dualidade entre corpo e alma, fazendo valer a ideia de que o corpo é significado por questões relativas à cultura e aos valores organizacionais.

Dale (2001) utiliza-se da expressão "absent presence", ou "presença ausente" para ilustrar que, embora os corpos estivessem sempre presentes como aparatos físicos envolvidos no trabalho, permaneceram ignorados pelos estudos organizacionais. Afirma, ainda, que as correntes teóricas mais gerencialistas em Administração atêm-se ao corpo somente como objeto a ser adaptado para o sistema de produção. Para tanto, o corpo é visto como o que deve ser mantido saudável e apto para produzir.

Essa lacuna nos estudos organizacionais remonta à separação cartesiana entre corpo e mente, compreendida como a base para a organização do trabalho mo- derno a partir de Taylor, que primou pela divisão entre a concepção mental e a execução braçal do trabalho, sendo a última considerada de menor valor (Dale, 2001).

A ideia de que o corpo é mais do que um aparato biológico natural está, entretanto, presente no pensamento de Hassard, Hollyday \& Willmot (2000). Para esses autores, o corpo é um constructo, ainda que convenções promovam o "esquecimento de como as zonas do corpo são arbitrariamente demarcadas e, por isso, vulneráveis à construção e reconstrução" (p. 2).

Nesse sentido, é importante pensar os corpos considerando também as questões de gênero. No que tange aos estudos organizacionais, o gênero aparece como uma questão física, na qual o corpo é entendido como aparelho biológico que determina o sexo do indivíduo (Dale, 2001). Os corpos de homens ou mulheres, sob a lógica dominante de racionalidade, devem produzir, independente de diferentes necessidades que possam surgir decorrentes das diferenças. Para as mulheres, muitas vezes os processos corporais constituem-se em obstáculos à sua plena participação, pois poucos são os espaços concedidos para lidar com "menstruação, lactação e tensão pré-menstrual" (Halford et al., 1997, citado por Hassard et al., 2000, p. 9).

Para além dos aspectos físicos, nos estudos organizacionais o feminino é visto como fora de lugar, o que faz com que as mulheres passem costumeiramente por mais dificuldades de inserção do que os homens, em especial nas atividades relacionadas à gestão (Gherardi, 1994). Mas as significações atribuídas ao feminino também acarretam a divisão do trabalho entre leve e pesado (Marcondes, Rotemberg, Portela, \& Moreno, 2003) ou classificações como profissões femininas - como áreas de suporte administrativo, de saúde e de assistência (Gherardi, 1994).

Ainda em relação às diferentes representações que circundam os corpos, Holliday \& Hassard (2001) apontam que essas se mostram capazes de situar desigualmente os indivíduos a partir de seus atributos. Os homens brancos heterossexuais e sem deficiências são colocados como a norma da qual as mulheres, os negros, os homossexuais e as pessoas com deficiência se afastam e diferenciam.

Hassard et al. (2000) afirmam que considerar o corpo nas suas relações com a gestão tem feito parte de pesquisas identificadas com postura teórica pós-moderna e feminista. Contudo, o significado atribuído ao corpo no contexto das corporações raramente tem sido discutido. Esses autores, assim como Flores-Pereira, Cavedon e Davel (2006), entendem que as práticas de organização e gestão são incorporadas, ou seja, vividas também corporeamente pelos trabalhadores.

Em suma, as práticas organizacionais estão diretamente ligadas ao desempenho do trabalho, sendo este, por sua vez, raramente apenas manual ou mental. 
Mesmo os trabalhos mais repetitivos exigem esforços mentais, além disso, o trabalho intelectual não é descorporificado, ainda que possa não exigir a força do corpo. Desse modo, ao mesmo tempo em que essas práticas organizam os corpos, atribuem-lhes sentidos e expectativas como as que se referem às questões gênero.

\section{Sobre a construção da pesquisa}

\section{A mídia escolhida}

A análise da cultura popular já foi empreendida por autores como Adorno \& Horkheimer (1985) e Strinati (1999). Nos estudos organizacionais, a análise a respeito do que é veiculado sobre gestão na mídia popular permite uma aproximação ao discurso vigente, corroborado tanto pelos experts que contribuem com essas publicações quanto pelo público-alvo, em geral formado por profissionais do mercado de trabalho, como demonstraram Wood Jr. e Paula (2002), Cappelle, Mageste, Mello e Brito (2003), Morin e Rodrigues (2004), e Mazza e Alvarez (2000).

A opção de trabalhar com a análise de uma revista popular de negócios justificou-se no entendimento de que essa mídia atua na divulgação e legitimação da lógica gerencialista, sendo mais um elemento disseminador desse pensamento. A Você S/A, mídia escolhida para esta pesquisa, é produzida e distribuída nacionalmente por uma editora de grande porte e se destaca pela facilidade de acesso ao público ao qual se destina, em especial, devido ao formato de textos curtos com linguagem acessível.

Strinati (1999) afirma que a cultura popular transmitida pelos meios de comunicação de massa assume importância cada vez maior sobre a vida dos indivíduos em culturas ocidentais. A imprensa popular é um meio eficiente para atingir milhares de pessoas, tendo sido utilizada também em sociedades totalitárias para fortalecer regimes e ideologias políticas.

Segundo Wood Jr. \& Paula (2002), tais mídias populares são validadas e têm seu peso potencializado pela presença de empresários ícones e gurus da área. Para Morin \& Rodrigues (2004), a mídia pode ser vista como uma prática discursiva, motivo pelo qual a análise de materiais daí provenientes oferece ao pesquisador a possibilidade de entendimento da construção de sentido de um determinado assunto em um contexto social.

A origem da Você $S / A$, de acordo com autores que também a utilizaram como fonte de pesquisa (Wood Jr. \& Paula, 2002; Cappelle et al., 2003), remete a outra revista da mesma editora, a Exame, lançada na década de 1960. De edições especiais dessa revista a respeito de carreira e qualificação profissional, nasceu a Você $S / A$, em 1998. Sua abordagem é dirigida aos profissionais individualmente, pois divulga temas de interesse pessoal dos mesmos, como gerenciamento de carreira, testes, relatos de experiência de executivos bem-sucedidos. Segundo os editores, o sucesso da publicação baseia-se neste caráter de autoajuda, que informa como estar no mercado de trabalho a partir de prescrições de comportamentos (Wood Jr. \& Paula, 2002).

A revista se constitui a partir de seções fixas e matérias variadas. No que concerne aos temas relacionados ao corpo, pode-se listar saúde, moda, produtos de luxo, tecnologia, e diversos, como o que vestir, o que comer, que exercícios praticar, o que comprar, como agir, entre outros fatores ligados às formas de vida dos seus leitores.

\section{Procedimentos metodológicos}

Esta pesquisa se caracteriza como um estudo exploratório-descritivo, uma vez que o objeto de estudo - representações do corpo - não foi ainda explorado no campo definido, a revista Você $S / A$. A apreciação dos dados deu-se a partir da análise de conteúdo (Bardin, 1979), que, além do caráter descritivo, permite algumas interpretações e inferências por parte do pesquisador acerca do material encontrado.

A análise de conteúdo seguiu orientações de Bardin (1979). A pré-análise, cujo objetivo é a organização dos documentos a serem investigados a partir de uma leitura flutuante, foi realizada nas doze edições selecionadas da revista, do período de julho de 2005 a junho de 2006. Nesse primeiro momento, foram obtidas as impressões gerais sobre a publicação e definidos como objetos de análise os textos das reportagens, sejam de seções fixas ou especiais.

Em seguida, passou-se para a exploração do material, momento em que os dados coletados na fase anterior foram analisados. O material foi, então, selecionado e organizado de acordo com a proximidade entre os assuntos e, a seguir, as reportagens foram sistematizadas segundo três grandes categorias: gênero, estilo (composta por estética e comportamento) e saúde, sendo que a última categoria foi posteriormente incorporada ao estilo, uma vez que tratava de comportamentos referentes aos cuidados com o corpo. Por fim, na fase de tratamento, inferência e interpretação dos dados, procurou-se o aprofundamento da análise, comparando-se os dados obtidos nos trabalhos análogos, além dos demais aportes teóricos oriundos dos estudos organizacionais, bem como de disciplinas afins, como a psicologia, filosofia ou mesmo antropologia.

\section{Análise das representações do corpo na revista estudada}

\section{Sobre gênero}

Iniciando-se as reflexões a partir da categoria relativa ao gênero, é possível considerar as múltiplas formas pelas quais se reforçam, na revista, os condicionamentos 
de gênero resultantes de diferentes significações atribuídas para homens e mulheres no espaço organizacional. Na grande maioria dos casos, os homens aparecem como naturalmente adaptados à carreira executiva $\mathrm{e}$ aos papéis de comando, ao mesmo tempo em que as mulheres trazem consigo a marca da diferença. As reportagens mostram elogiosamente empresas que aceitam e promovem suas funcionárias ou que contratam executivas, como parte das políticas de apoio à diversidade. Explicitam, nesses casos, que se trata de um movimento em favor delas, visto que a corporação não é mostrada como lugar óbvio para o feminino.

Conforme visto em Butler (2003), é possível inferir que esta universalidade que emparelha masculino a humano impõe, consequentemente, a diferença para as mulheres. Na revista pesquisada são corroboradas as ideias vigentes no senso comum que rodeia as organizações: a manutenção dos papéis polarizados de homens e mulheres, a difícil entrada dessas no mundo corporativo, bem como a maternidade como grande desafio feminino a ser conjugado com uma vida profissional.

As reportagens sobre e para mulheres evidenciaram preocupações com a maternidade e o acúmulo de papéis, bem como cuidados com a saúde. Na edição de setembro de 2005, o artigo "Mães Executivas", apesar de uma postura favorável à maternidade, mostrava que as mães executivas são minoria e recebem salários percentualmente menores do que homens no desempenho das mesmas atividades. Dentre as executivas referidas na reportagem, todas foram mães após os 30 anos de idade, sendo que algumas mencionaram dificuldades para engravidar. Foi consenso entre as entrevistadas um sentimento de insegurança sobre a manutenção do emprego quando souberam da gravidez, mas, tendo mostrado altos esforços - algumas afirmaram ter aumentado sua carga de trabalho antes do parto - não apenas permaneceram na empresa como foram promovidas. $\mathrm{O}$ empenho, a ambição e competitividade foram a contrapartida que essas mulheres mostraram em relação à sua condição de mães e isso tornou possível a sua permanência.

Na medida em que as exigências do mercado se corporificam em favor da competitividade, pode-se identificar a atuação da biopolítica. $\mathrm{O}$ acúmulo das responsabilidades profissionais e maternas, além de outros compromissos, fazem lembrar a categoria de super-mulher dotada de imensa flexibilidade, capacidade de ser profissional destacada, boa mãe, esportista e dona de casa, apontada por Cappelle et al. (2003). Além disso, faz-se ver que, num espaço tido como masculino, as mulheres precisam despender significativamente mais energias, ou ainda enfrentar renúncias para legitimarem-se nos papéis de comando.

A matéria refere, ainda, alguns setores do mercado como mais abertos do que outros à entrada das mulheres, como é o caso do ramo de bens de consumo em comparação ao financeiro. São referidos fabricantes de alimentos, bebidas, sapatos e fraldas como mais favoráveis, o que possibilita questionar se a razão disso não está justamente em serem produtos de um dito universo feminino. Do mesmo modo, Cappelle et al. (2003) observaram que, na revista Exame, as mulheres estão presentes em reportagens sobre esses mesmos assuntos; e Assis, Gontijo, Corrêa \& Bittencourt Neto (2004) observaram que jornais voltados para o público feminino versavam sobre receitas culinárias, cuidados com a beleza e relacionamentos. A literatura internacional refere, igualmente, a segregação ocupacional de mulheres em alguns setores da economia (Ben, 2007; Crump, Logan, \& McIlroy, 2007; Larsen, 2006).

Já na edição de fevereiro de 2006 da Você $S / A$, a matéria "Mulheres em Risco" abordava a saúde física das mulheres inseridas no mercado de trabalho com o seguinte mote: "Ao ingressar no mercado de trabalho e incorporar a rotina estressante dos homens, as mulheres passaram a ter quase tantos problemas de coração quanto eles" (Lacerda, 2006, p. 86). Cappelle et al. (2003) também fazem menção aos reflexos dessa sobreposição de atividades profissionais e domésticas à saúde da mulher. Tal afirmação remete às questões biológicas que são frequentemente mencionadas para explicar a separação de papéis masculinos e femininos, e que foram rebatidas pelos movimentos feministas. Collier, Rosaldo e Yanagisako (1992) questionam a naturalização do feminino, pois a divisão de funções que delega às mulheres o cuidado com os filhos faz uso do dado biológico para justificar o que é algo construído no social.

Além do feminino, o masculino é também retratado na revista. Embora os homens não sejam frequentemente analisados como sujeitos generificados no mundo do trabalho pelos estudos organizacionais, Eccel e Grisci (2009) afirmam a necessidade de considerá-los sob a perspectiva da masculinidade e de suas vivências de gênero. As autoras apontam para diversas vivências de masculinidades simultâneas em uma empresa de grande porte, revelando desníveis de legitimação e poder entre os homens, bem como o fazem os estudos de Connell (1998) e Kimmel (1998).

Acerca das masculinidades, Connell (1998) refere que as diferenças de poder fazem com que algumas masculinidades se tornem hegemônicas. Entendidas como as maneiras normais e certas de se viver como homem em cada contexto, as masculinidades hegemônicas subjugam outras, vistas como desviantes. O gênero é um regime classificatório que opera também entre os homens, possibilitando hierarquias entre eles.

Connell e Wood (2005) sugerem que a figura do executivo global assume, na contemporaneidade, o lugar de masculinidade hegemônica. A masculinidade de negócios transnacionais é representada na Você $S / A$ 
por homens que detêm o poder financeiro e decisório, com mobilidade, acesso a tecnologias, caracterizados pelo egocentrismo e lealdades condicionais mesmo com as corporações que os empregam.

A possibilidade de afastar-se desse modelo é apresentada na revista em maio de 2006, sob o título "O Novo Homem". A matéria mostra executivos que passaram a dar uma importância maior à família do que ao trabalho, o que gera certo espanto tanto entre os executivos homens quanto entre as mulheres, pois rompe com os papéis estereotipados de gênero. $\mathrm{O}$ entrevistado em foco revela que trocou uma rotina diária de intenso trabalho por um negócio próprio para poder ficar mais perto da filha. A mudança no perfil dos homens passa necessariamente por uma mudança profissional, como exemplifica o ex-gerente e, de acordo com a matéria, uma das motivações para essa transformação foi a maior participação das mulheres nas corporações. Oliveira (2004) refere que mudanças nas instituições sociais tradicionais, como a família, geram também mudanças no que se espera dos homens.

Embora sejam anunciadas possibilidades de circulação entre os papéis tradicionais de homens e mulheres, a prevalência deles em posições de comando segue incontestável. Cappelle et al. (2003) mencionaram que em uma reportagem de 2003 sobre CEOs do futuro, a Você $S / A$ apresentava uma única mulher entre 20 homens. Passados alguns anos, uma nova versão da mesma reportagem, editada em fevereiro de 2006, apresenta 12 homens e três mulheres. Em outra matéria de junho de 2006, a revista apresentou dez executivos de grande destaque com menos de 40 anos, entre os quais apenas três eram mulheres. A sub-representação feminina em cargos de alto escalão (Simpson \& Lewis, 2005), bem como as diferenças salariais (Joshi, Makepeace, \& Dolton, 2007), são largamente apresentadas na literatura internacional.

Essas discussões remetem ainda ao trabalho de O'Sullivan \& Sheridan (1999), que analisaram representações das figuras femininas em filmes e séries de televisão, e identificaram que essas mídias refletem percepções negativas dos papéis femininos no mundo corporativo. Segundo as autoras, dificilmente as mulheres aparecem em cargos seniores, e aquelas que chegam a esses postos reproduzem características tipicamente masculinas, destacando preconceitos contra as mulheres. Além disso, apresentam dois fatores que indicam dificuldades nos avanços das figuras femininas no meio organizacional: os estereótipos de que mulheres adotam características masculinas para obterem sucesso no mundo dos negócios; e a reprodução homossocial, ou seja, a ideia de que aqueles que se encontram em posições de gestão preferem promover pessoas com características sociais semelhantes às suas, com o objetivo de manterem-se próximos do poder. Segundo as autoras, essas mídias legitimam a ideia de que, diferentemente das mulheres, os homens são naturalmente preparados para a liderança.

$\mathrm{O}$ tema da diversidade no que tange às vivências de gênero não foi apresentado na revista $\operatorname{Você} S / A$. As referências limitaram-se a uma oposição binária das imagens tradicionais do masculino e do feminino, não considerando outras possibilidades, como homens ou mulheres homossexuais, travestis ou transexuais. De certo modo, tal constatação vem referendar o fato de que, apesar dos discursos inclusivos, o mundo corporativo tem se mostrado um tanto fechado para discussões relativas à diversidade de orientação sexual.

\section{Sobre estilo - estética e comportamento}

Dentre as mudanças pelas quais tem passado o corpo na sociedade de consumo, aquelas que se referem à estética e ao comportamento destacam-se com maior relevo, tendo no trabalho, mesmo quando imaterial, o corpo em evidência. Em razão disso, padrões de controle e manutenção do corpo propagam-se como essenciais para o bem-estar pessoal e para o reconhecimento profissional. No mundo dos negócios, a formação de estereótipos relacionados ao estilo torna-se evidente, e o tema ocupa significativo espaço na revista Você $S / A$. As reportagens relacionadas aos cuidados com a saúde do corpo, formas de vestir ou se comportar apresentam como modelo de referência a figura do executivo de sucesso.

A edição de novembro de 2005 contempla, como assunto de capa, a necessidade de investir no visual, considerando-o como um fator determinante para o sucesso na carreira, em especial na conquista de uma vaga. A reportagem descreve, minuciosamente, a maneira correta de vestir-se e comportar-se no dia-a-dia de trabalho ou em uma entrevista de seleção para emprego. Além disso, destaca frases como: "O peso da imagem"; "bonitos e ricos"; ou ainda "pesquisa norte-americana revela: cada polegada a mais na altura equivale a $1,8 \%$ a mais no salário", justificando o título "Aparência Importa Sim" (Diniz, 2005a, p. 22-29). De certo modo, há uma reprodução da ideia predominante de que as pessoas são a "vitrine" da empresa, necessitando estar sempre bem alinhadas para representá-la. O apelo para essa boa apresentação, entretanto, se manifesta por meio dos fatores financeiros que estão diretamente ligados à imagem pessoal, principalmente em relação aos cuidados com o corpo.

Cabe destacar que a reportagem em sequência trazia dicas referentes ao "Visual Nota 10", contemplando assuntos como cores de roupas, tipos de sapatos, meias e acessórios, entre outros. Amesma edição apresentou uma reportagem sobre o estilo pessoal de vestir de dois executivos bem-sucedidos que destacaram a importância de se sentirem confortáveis no ambiente de trabalho. Além disso, são representativas duas colunas de circulação fixa. A primeira, com o título "Você Merece", oferece 
matérias e sugestões referentes a roupas, calçados, produtos de beleza, acessórios; demonstra o estilo de vida de profissionais e a maneira de vestir em algumas empresas. A segunda coluna, intitulada "Etiqueta no Trabalho", fornece dicas de uma consultora de etiqueta empresarial sobre como se comportar nos ambientes de trabalho, no escritório, nas viagens, nos jantares, entre outros.

Ambas as colunas vêm demonstrar que a incorporação dos estilos é diretamente associada ao desempenho profissional, mesmo que o indivíduo não esteja em seu horário de expediente, reduzindo significativamente a possibilidade de se dissociar vida pessoal da vida no trabalho. É possível perceber também, baseando-se na argumentação de Pelbart (2003), que não são apenas os produtos e serviços que passam a ser vistos como os elementos-chave das organizações, mas as formas de vida e as relações desempenhadas pelos sujeitos que as compõem que, constantemente, devem ser rentabilizadas no desempenho de seu trabalho.

A beleza física buscada por meio dessas estratégias tem sido valorizada no ambiente de negócios e, embora não seja diretamente referida nos discursos organizacionais, atua desde a oportunidade de contratação até as possibilidades de ascensão e permanência na empresa, conforme atestam os estudos de Grisci, Becker, Scalco e Kruter (2008).

Ainda no que tange à aparência, são importantes as questões relativas ao peso do corpo. As reportagens da Você $S / A$ sobre saúde enfatizam dietas equilibradas e a prática de exercícios físicos. São oferecidas desde dicas quanto aos melhores alimentos a serem consumidos até quanto aos equipamentos para a prática de esportes. Uma dessas reportagens demonstra os benefícios da atividade física refletidos diretamente no ambiente profissional, tendo por base o depoimento de executivos e profissionais de educação física. A rentabilização dos indivíduos deve se manifestar mesmo fora do trabalho, em hábitos de vida saudável, práticas de atividades físicas e outras atividades que enaltecem a sociedade de consumo.

$\mathrm{Na}$ edição de setembro de 2005 da Você $S / A$, a saúde do indivíduo é abordada de uma maneira ampla, destacando as consequências provocadas pelo estresse. Sob o título "O Trabalho Aterroriza a Saúde" (Schibuola, 2005, p. 42), são trazidos à discussão os sintomas físicos, emocionais e comportamentais. Entre eles, encontram-se dores, cansaço crônico, insônia, distúrbios gastrointestinais, ansiedade, irritação, consumo exagerado de álcool e cigarros, aumento da agressividade, distúrbios de apetite e mudanças da libido. Porém, o sofrimento é apresentado como assunto de caráter individual, e não são questionadas as condições de trabalho, como carga de atividades, responsabilidades, cobranças e competitividade. Tal constatação está de acordo com as ideias apontadas por Gaulejac (2007, p. 45) de que os discursos gerencialis- tas, com foco no capitalismo financeiro, acarretam uma "despersonalização das fontes de poder", o que, por sua vez, resulta na necessidade de que o trabalhador se torne gestor de si com o objetivo de frutificação dos lucros.

Nessa mesma linha, é possível perceber que as políticas de gestão atuais que enfatizam a flexibilidade, apesar de parecerem mais humanas e participativas, não resultam em melhorias na qualidade de vida do trabalhador. A responsabilidade sobre a saúde recai sobre o profissional, que deve estar sempre pronto para o trabalho. Nessa perspectiva, é possível traçar um paralelo com os estudos de Lupton (2000), ao destacar as diversas instituições responsáveis pela disseminação e manutenção de discursos que interferem na governamentabilidade dos corpos, como o Estado, a cultura, a família, o sistema judiciário e a mídia; bem como as ideias de Foucault (2008) referentes ao governo dos corpos por meio da biopolítica que, na lógica neoliberal, passa a ser estabelecido não só por tais instituições, mas pelo próprio mercado.

De modo geral, na pesquisa realizada, foi possível verificar que as dicas e sugestões relacionadas ao estilo de vida e à saúde dos profissionais reproduzem e legitimam algumas "verdades" ligadas à ideia de corpo e estilo - estética e comportamento - que são demandados nos ambientes de trabalho. Apesar da modernidade líquida não mais se basear em fatores disciplinares, a docilização dos corpos ainda se mostra como um elemento importante para o gerenciamento. A introjeção da forma de controle sinóptico (Bauman, 1999) e, consequentemente, a responsabilização individual, permitem que as fontes de poder intensifiquem a despersonalização dos discursos gerenciais, fazendo com que cada indivíduo passe a controlar não somente os fatores relativos ao desempenho no trabalho, mas as mais diversas características relativas aos seus modos de vida.

Um outro ponto a ser destacado corresponde ao fato de que, nas 12 edições analisadas, a deficiência física foi mencionada apenas duas vezes: em setembro de 2005 , em uma reportagem que mostrava dois profissionais que conseguiram superar a gagueira e atingir sucesso em suas funções, e em novembro de 2005, em uma breve nota em seção de variedades a respeito a necessidade de adaptação dos colegas. A pouca ênfase com que o assunto foi trabalhado na publicação merece destaque, visto que esse mesmo tema tem sido enfatizado em outros fóruns, em especial em função da lei de cotas para pessoas com deficiência nas organizações. Supõe-se que essa questão relaciona-se à dificuldade em lidar com o diferente, com aquilo que escapa a um modelo disseminado, que, segundo Tucherman (2004), sempre acompanhou a humanidade.

Cabe ressaltar as menções referentes às reportagens que apresentam as categorias de gênero e estilo em conjunto. Tais reportagens, na maioria das vezes, 
referiam-se às vestimentas a serem utilizadas distintamente por homens e mulheres. Destaca-se a edição de novembro de 2005 que, dentre algumas dicas para uma boa aparência, faz notar fatores relacionados ao uso de meias, relógios e terno adequado para os homens, e meias-calças, colares de pérolas, salto alto e tailleur para mulheres (Diniz, 2005b, pp. 30-31).

Referindo-se a essa ideia, por meio de uma pesquisa sobre questões de gênero e corpo na atualidade, Goldenberg (2004) aponta para a contradição entre uma suposta liberdade da sociedade atual versus os valores tradicionais que impõem padrões tanto a homens quanto a mulheres. Nesse sentido, para os homens as questões de poder, prestígio, força física e virilidade aparecem como atributos fundamentais, frutos de uma idealização infantil. As mulheres, ao mesmo tempo em que almejam maior autonomia pessoal e profissional, lutam e sofrem para adquirir formas físicas nada liberais. Tratam-se aqui de modelos de masculinidade e feminilidade que extrapolam o corporal, mas não o excluem, e que atuam como imperativos a serem buscados para a ocupação de um espaço social.

\section{Considerações finais}

A presente pesquisa procurou analisar como uma revista de negócios representa o corpo através do que veicula em suas reportagens. As representações encontradas foram categorizadas em dois grupos: gênero e estilo. Embora a análise tenha tratado-os separadamente, eles, sem dúvida, se sobrepõem e se reforçam mutuamente. Desse modo, salienta-se que a representação do corpo na revista Você $S / A$ ressalta o regime de gênero que mantém a dicotomia masculino/feminino, já criticada por Butler (2003), e as prescrições sobre como apresentar e conduzir o corpo nas mais diversas situações do trabalho e da vida pessoal. É nesse sentido que a vida pessoal, na maioria das vezes, subordina-se ao trabalho.

A partir dessas análises é possível realizar uma leitura do discurso gerencial que, ao mesmo tempo em que afirma como positivas as atitudes de independência, criatividade e autonomia, exige que os profissionais se moldem aos estilos de vida resultantes dos modos de subjetivação compatíveis com o trabalho na modernidade líquida, como denominada por Bauman (2001). Nesse sentido, foi possível constatar que os artigos apresentados pela Você $S / A$ são, em sua maioria, prescritivos e apontam maneiras de adaptar-se aos modelos vigentes de corpo e gênero valorizados corporativamente.

Além disso, visto que se trata de uma mídia representativa da ideologia capitalista, ela dissemina como valores o individualismo, a competitividade, autossuperação e dedicação extrema ao trabalho. Se o assunto remetia a algum tipo de sofrimento no mundo corporativo, esse era apresentado de forma positiva, como algo que pôde ser superado e trouxe crescimento, sugerindo uma não resistência aos dissabores profissionais, e, enfim, uma docilização dos corpos para o trabalho (Foucault, 1977/1996), em função das exigências de governamentabilidade determinada pela lógica do neoliberalismo (Foucault, 2008).

Ademais, a análise das representações do corpo na revista Você $S / A$ permitiu discutir a naturalização do corpo na gestão. A noção predominante nas linhas gerencialistas de Administração é a do corpo como instrumento de trabalho não problematizável. As abordagens teóricas trazidas propõem o entendimento de que o corpo é social e culturalmente construído, e que tem sido utilizado como base para classificar e hierarquizar indivíduos nas organizações (Flores-Pereira, Cavedon, \& Davel, 2006; Holliday \& Hassard, 2001; Hassard, Hollyday \& Willmot, 2000).

Finalmente, mas sem esgotar a discussão, destacase que a pesquisa foi empreendida tomando por base 12 edições de uma única publicação no período de um ano, o que pode restringir o olhar e caracterizar uma limitação do estudo. Para pesquisas futuras, sugere-se a abordagem de outras mídias também legitimadas no dia-a-dia das organizações empresariais, ou ainda, a realização de pesquisas com um recorte temporal mais amplo, com o objetivo de verificar o encaminhamento desses discursos no decorrer do tempo.

\section{Referências}

Adorno, T. W. \& Horkheimer, M. (1985). Dialética do esclarecimento: fragmentos filosóficos. Rio de Janeiro: J. Zahar.

Assis, L. B., Gontijo, M. C. L., Corrêa, A. M. H., \& Bittencourt Neto, E. (2004). Jornais de circulação interna: a reprodução das representações sociais do feminino e do masculino no chão-de-fábrica. In Anais do XXVIII Encontro da ANPAD [CD-ROM]. Curitiba: ANPAD.

Bardin, L. (1979). Análise de conteúdo. Lisboa: Ed. 70.

Bauman, Z. (1999). Globalização: as conseqüencias humanas. Rio de Janeiro: Jorge Zahar.

Bauman, Z. (2001). Modernidade líquida. Rio de Janeiro: Jorge Zahar.

Ben, E. (2007, July). Defining expertise in software development while doing gender. Gender, Work and Organization, 14(4), 312-332.

Butler, J. (2003). Problemas de gênero: feminismo e subversão da identidade. Rio de Janeiro: Civilização Brasileira.

Cappelle, M. C. A., Mageste, G. S., Mello, M. C. O. L., \& Brito, M. J. M. A. (2003). Representação feminina na mídia de negócios. In Anais do XXVII Encontro da ANPAD [CD-ROM]. Atibaia, SP: ANPAD.

César, M. R. de \& Duarte, A. (2009, maio-agosto). Governo dos corpos e escola contemporânea. Educação \& Realidade, $32(2), 119-134$

Collier, J., Rosaldo, M., \& Yanagisako, S. (1992). Is there a family: New anthropological views. In B. Thorn \& M. Yalom (Orgs.), Rethinking the family: Some feminist questions (pp. 31-48). Boston: Northeastern University Press. 
Connell, R.W. (1998, July). Masculinities and globalization. Men and Masculinities, 1(1), 3-23.

Connell, R. W. \& Wood, J. (2005, April). Globalization and Business Masculinities. Men and Masculinities, 7(4), 347 - 364.

Crump, B., Logan, A., \& McIlroy, A. (2007, July). Does gender still matter? A study of the views of women in the ICT Industry in New Zealand. Gender, Work and Organization, 14(4), 333-348.

Dale, K. (2001). Anatomising embodiment and organisation theory. Basingstoke: Palgrave.

Diniz, D. (2005a, novembro). Aparência importa sim. Você S/A, 8(89), 22-29.

Diniz, D. (2005b, novembro). 8 truques para um visual nota 10. Você $S / A, 8(89), 30-31$.

Eccel, C. S. \& Grisci, C. L. I. (2009). Trabalho e gênero: a produção de masculinidades na perspectiva de homens e mulheres. In Anais do XXXIII Encontro da ANPAD [CD-ROM]. São Paulo: ANPAD.

Flores-Pereira, M. T., Cavedon, N. R., \& Davel, E. (2006). O corpo como artefato: botando corpo nos estudos de cultura organizacional. In Anais do XXX Encontro da ANPAD [CDROM]. Salvador: ANPAD.

Gaulejac, V. (2007). Gestão como doença social. Aparecida: Idéias \& Letras.

Foucault, M. (1996). Vigiar e punir: nascimento da prisão (13 ed.). Petrópolis, RJ: Vozes. (Original publicado em 1977)

Foucault, M. (2008). Nascimento da biopolítica. São Paulo: Martins Fontes.

Gherardi, S. (1994). The gender we think the gender we do in our everyday organizational lives. Human Relations, 47(6), 591-611.

Grisci, C. L. I., Becker, J. L., Scalco, P. D., \& Kruter, G. E. (2008). A beleza física no contexto do trabalho imaterial bancário. In Anais do XXXII Encontro da ANPAD [CD-ROM]. Rio de Janeiro: ANPAD.

Goldenberg, M. (2004). De perto ninguém é normal. Estudos sobre corpo, sexualidade, gênero e desvio na cultura brasileira. Rio de Janeiro: Record.

Hassard, J., Hollyday, R., \& Willmot, H. (2000). Bodies and organization. London: Sage Publications.

Hollyday, R. \& Hassard, J. (2001). Contested bodies: An introduction. In R. Hollyday \& J. Hassard (Edits.), Contested bodies (pp. 91-112). London: Routledge.

Joshi, H., Makepeace, G., \& Dolton, P. (2007, January). More or less unequal? Evidence on the pay of men and women from the British birth cohort studies. Gender, Work and Organization, 14(1), 37-55.

Kimmel, M. S. (1998, outubro). A produção simultânea de masculinidades hegemônicas e subalternas. Horizontes Antropológicos, ano 4, 9, 103-117.

Lacerda, D. (2006, fevereiro). Mulheres em risco. Você $S / A$, $9(92), 86$.

Larsen, E. (2006, July). The impact of occupational sex segregation on family businesses: The case of American harness racing. Gender, Work and Organization, 13(4), 359-382.

Lazzarato, M. \& Negri, A. (2001). Trabalho imaterial: formas de vida e produção de subjetividade. Rio de Janeiro: DP\&A.

Lupton, D. (2000, julho- dezembro). Corpos, prazeres e práticas do eu. Revista Educação \& Realidade, 25(2), 45-58.

Louro, G. L. (2000). Corpo, escola e identidade. Educação e Realidade, 25(2), 59-75.

Marcondes, W., Rotemberg, L., Portela, L., \& Moreno, C. (2003). O peso do trabalho "leve" feminino à saúde. São Paulo em Perspectiva, 17(2), 91-101.
Mazza, C. \& Alvarez, J. L. (2000). Haute couture and prêt-aporter: The popular press and the diffusion of management practices. Organization Studies, 21(3), 567-588.

Morin, E. \& Rodrigues, A. L. (2004). Mídia e reconhecimento profissional: a análise de conteúdo como recurso para exploração de práticas discursivas e impactos na qualidade de vida no trabalho de executivos. In Anais do XXVIII Encontro da ANPAD [CD-ROM]. Curitiba: ANPAD.

Oliveira, P. P. (2004). A construção social da masculinidade. Belo Horizonte: UFMG; Rio de Janeiro: IUPERJ.

O'Sullivan, J. \& Sheridan, A. (1999). Ms representations: Women, management and popular culture. Women in management review, 14(1), 14.

Pelbart, P. P. (2003). Vida capital: ensaios de biopolítica. São Paulo: Iluminuras.

Sant'Anna, D. (2001). Corpos de passagem: ensaios sobre a subjetividade contemporânea. São Paulo: Estação Liberdade.

Schibuola, T. (2005, novembro). O Trabalho aterroriza a saúde. Você S/A, 8(89), 42.

Simpson, R. \& Lewis, P. (2005). An investigation of silence and a scrutiny of transparency: Re-examining gender in organization literature through the concepts of voice and visibility. Human Relations, 58(10), 1253-1275.

Strinati, D. (1999). Cultura popular: uma introdução. São Paulo: Hedra.

Tucherman, I. (2004). Breve história do corpo e seus monstros ( $2^{\mathrm{a}}$ ed.). Lisboa: Passagens.

Wood Jr., T. \& Paula, A. P. P. (2002). Pop-management: pesquisa sobre as revistas populares de gestão no Brasil. In Anais do $X X X$ Encontro da ANPAD [CD-ROM]. Salvador: ANPAD.

Recebido em: 04/10/2008

Revisão em: 03/09/2009

Aceite final em: 05/01/2010

Cláudia Sirangelo Eccel é Doutoranda e mestre em Administração pela Universidade Federal do Rio Grande do Sul (UFRGS). Psicóloga graduada pela UFRGS. Endereço: Escola de Administração da UFRGS. Rua Washington Luiz, 855/424. Porto Alegre/RS, Brasil. CEP 90010-460. Email: claudiaeccel@hotmail.com

Carmem Lígia Iochins Grisci é Doutora em Psicologia pela Pontifícia Universidade Católica do Rio Grande do Sul. Pós-doutorado pela Universidade Técnica de Lisboa.

Professora do PPG em Administração da Universidade Federal do Rio Grande do Sul. Pesquisadora CNPq.

Leonardo Tonon é Doutorando e mestre em Administração pela Universidade Federal do Rio Grande do Sul, bacharel em Administração pela Universidade Estadual de Maringá.

\section{Como citar:}

Eccel, C. S., Grisci, C. L. I. \& Tonon, L. (2010). Representações do corpo em uma revista de negócios. Psicologia \& Sociedade, 22(2), 309-317. 